\title{
Effects of the Presence of the Doula on Pregnant Women's Anxiety and Pain During Delivery: A Randomized Controlled Trial
}

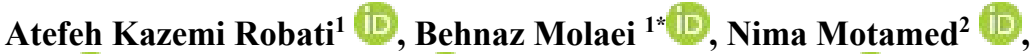 \\ Robabeh Hatami $^{1}$ (D), Hamideh Gholami ${ }^{1}$ (D), Anita Ahmadi Birjandi ${ }^{3}$ (D) , Mina Esmkhani ${ }^{4}$ (D)
}

1. Dept. of Obstetrics and Gynecology, Zanjan University of Medical Sciences, Zanjan, Iran

2. Dept. of Social Medicine, Zanjan University of Medical Sciences, Zanjan, Iran

3. Zanjan University of Medical Sciences, Zanjan, Iran

4. Dept. of Midwifery, Faculty of Nursing and Midwifery, Zanjan University of Medical Sciences, Zanjan, Iran

\section{Article Info \\ 10.30699/jambs.28.131.296 \\ Received: 2019/11/23; \\ Accepted: 2020/06/12; \\ Published Online: 01 Oct 2020 \\ Use your device to scan and read the article online

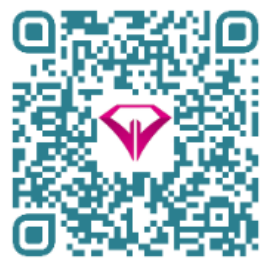

Corresponding Information: Behnaz Molaei,

Dept. of Obstetrics and Gynecology, Zanjan University of Medical Sciences, Zanjan, Iran

E-Mail:

molaei@zums.ac.ir

\section{ABSTRACT}

Background \& Objective: Doulas can ease labor and delivery in a hospital); however, in Iran, few studies have been conducted on this topic because of the cultural and structural boundaries. Therefore, this study aimed to evaluate the impact of a doula's presence on anxiety and pain in pregnant women during the delivery process.

Materials \& Methods: This randomized clinical trial was conducted on 80 pregnant women referred to Ayatollah Musavi Hospital (Zanjan, Iran) in 2016. For women in the intervention group, the doula provided emotional and physical support. The mothers' pain severity and anxiety were measured by using a visual analog scale (VAS) and Spielberger questionnaire, respectively. Categorical and continuous variables were compared using chi-square and $t$ tests, respectively.

Results: We found that a higher proportion of patients had experienced mild anxiety about entering the postpartum period ( $47.5 \%$ vs $15 \%)$ and exiting it ( $80 \%$ vs $40 \%$; $P<0.05$ ) compared to the control group. Also, the mean VAS score was significantly higher in the control group at $4-5 \mathrm{~cm}(86.5 \pm 11.39$ vs $78.62 \pm 14.0 ; P=0.007)$ and $7-8$ $\mathrm{cm}$ of cervical dilatation $(99.0 \pm 4.41$ vs $95.0 \pm 8.47 ; P=0.01)$ stages.

Conclusion: The presence of a trained doula during labor can ease the mental consequences of delivery and decrease women's anxiety and pain during labor.

Keywords: Doulas, Labor, Emotions, Anxiety, Pain 
was significantly lower than that of the other groups (6). Also, the results of another study showed that the presence and support of pregnant women's family during delivery would reduce pain and concern and increase the physical and mental health of the mothers as well as the sense of well-being (10).

Still, the question remains whether the presence of doulas through pregnancy has any effect on the delivery's outcomes. Previous studies have shown that training pregnant women and clarifying their roles during delivery, as well as the manner of providing support, would enhance the outcomes of delivery (11).

Studies have shown that doulas can ease labor and delivery in ahospital; however, in Iran, few studies have been conducted on thistopic because of the cultural and structural boundaries. Therefore,this study aimed to evaluate the impact of a doula's presence onanxiety and pain in pregnant women during the delivery process.

\section{Materials and Methods}

\section{Study Design}

This randomized clinical trial was conducted on 80 pregnant women referred to the Ayatollah Musavi Hospital (Zanjan, Iran) in 2016. We randomly assigned the patients into the doula support $(n=40)$ and control groups $(n=40)$. Balanced block randomization (block size $=4$ ) was performed to allocate the patients to the mentioned groups.

\section{Eligibility Criteria}

We included patients with the following criteria: age 18-40 years, gestational age $>37$ weeks, lack of obvious chromosomal abnormalities and fetal anomalies, normal AFI: Amniotic Fluid Index ,the full phrase is correct (5$24 \mathrm{~cm})$, normal BioPhysical Profile (BPP) (8-10), fetal cephalic presentation, single pregnancy, and education level of at least middle school. The mothers' disagreement to participation, presence of underlying diseases, intrauterine fetal death (IUFD), any signs of fetal distress, clear fetal abnormalities, placenta previa, placental abruption, suffering from any physical or mental disorder, and receiving any kind of medication were considered as the exclusion criteria.

\section{Study Procedure}

For women in the intervention group, the doula provided emotional support (use of encouraging phrases about the nature of labor pain, effect of pain intensity on the progress of labor, touching and massaging the mothers' back, answering mothers' questions about the progress and success of delivery, providing essential education during labor (how to breathe, correct positioning in different stages), and physical support (helping the mothers to change their position, accompanying the mother, need to move out of bed). The women in the control group (without doula support) only received routine care. The doula was a midwife with a master's degree or a bachelor's degree trained in physiological delivery. The time spent in the maternity ward was from the time of admission and the start of the active phase to delivery and the postpartum period. Separate labor rooms were chosen for each patient, or the beds were screened to prevent contamination between the doula groups.

\section{Measurement Tool}

We used a visual analog scale (VAS) at the time of presentation to the maternity unit for recording pain severity. VAS was employed at cervical dilatations of $<$ $4 \mathrm{~cm}, 4-5 \mathrm{~cm}, 7-8 \mathrm{~cm}$, and $9-10 \mathrm{~cm}$, with 0 representing no pain and 10 representing the worst possible pain.

Mothers' anxiety was measured using the Spielberger questionnaire. This instrument contains 20 items for measuring trait anxiety and 20 for measuring state anxiety. Each item is scored from 1 to 4 , and patients with greater anxiety receive a higher score. At least a sixth-grade reading level is necessary to complete this questionnaire. The reliability of this questionnaire was previously confirmed in Iran (12).

The Spielberger questionnaire was completed by the mothers in each stage. Since the trait anxiety is not affected by the situation and is considered as the basic anxiety, the scale was completed only once at the beginning of the study by the participants of both groups. However, the state anxiety scale was completed in four stages: at $4-5 \mathrm{~cm}$ and $7-8 \mathrm{~cm}$ cervical dilations, first hour after the delivery, and at the end of the admission. VAS was also used at the time of 4-5 cm, 7-8 cm, and 9-1 cm cervical dilations, as well as the beginning of the entrance to the post-room and time of departure from the labor room.

\section{Data Analysis}

Qualitative data were presented with frequency and percentage, and quantitative data were shown with mean \pm SD. Categorical and continuous variables were compared using chi-square and $t$ tests, respectively. All the analyses were performed in SPSS 23 (SPSS Inc., Chicago, Ill., USA), and a P-value $<0.05$ was considered as significant.

\section{Results}

First, 93 cases were enrolled, and then nine people were excluded later (Figure 1). Therefore, statistical analyses were performed on 80 cases (40 control subjects and 40 intervention cases).

Table 1 presents the demographic characteristics of both groups. The results revealed a significant difference between the two groups in terms of parity, Vaginal Delivery (NVD), and education $(P<0.05)$. However, the mean age difference between the two groups was not statistically significant $(31.3 \pm 3.9$ years in the doula group vs $31.3 \pm 4.2$ years in the control group; $P=0.22$ ) 


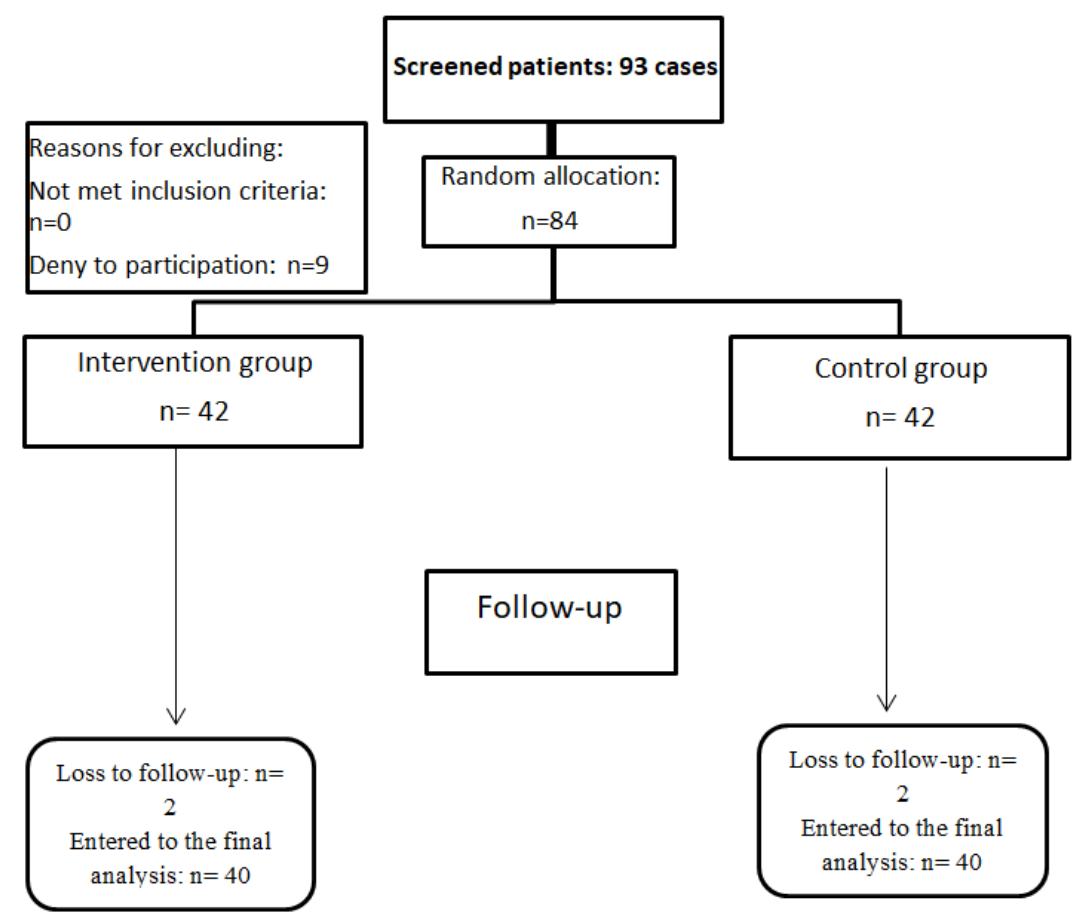

Figure 1. Flow diagram of the study

Table 1. Demographic characteristics of the two groups

\begin{tabular}{|c|c|c|c|c|}
\hline \multicolumn{2}{|r|}{ Variable } & $\begin{array}{c}\text { Control group } \\
\text { N }(\%)\end{array}$ & $\begin{array}{c}\text { Doula group } \\
\text { N }(\%)\end{array}$ & P-value \\
\hline \multirow{6}{*}{ Parity } & 0 & 0 & $2(5.0)$ & \multirow{6}{*}{0.004} \\
\hline & 1 & $11(27.5)$ & $24(60)$ & \\
\hline & 2 & $15(37.5)$ & $7(17.5)$ & \\
\hline & 3 & $9(22.5)$ & $7(17.5)$ & \\
\hline & 4 & $4(10.0)$ & 0 & \\
\hline & 5 & $1(2.5)$ & 0 & \\
\hline \multirow{6}{*}{ NVD } & 0 & 0 & $2(5.0)$ & \multirow{6}{*}{0.007} \\
\hline & 1 & $12(30.0)$ & $26(65.0)$ & \\
\hline & 2 & $16(40.0)$ & $7(17.5)$ & \\
\hline & 3 & $7(17.5)$ & $5(12.5)$ & \\
\hline & 4 & $4(10.0)$ & 0 & \\
\hline & 5 & $1(2.5)$ & 0 & \\
\hline \multirow{3}{*}{$\begin{array}{l}\text { Level of } \\
\text { education }\end{array}$} & Below high-school diploma & $4(10.0)$ & $3(7.5)$ & \multirow{3}{*}{0.002} \\
\hline & High-school diploma & $28(70.0)$ & $14(35.0)$ & \\
\hline & Academic & $8(20.0)$ & $23(57.5)$ & \\
\hline
\end{tabular}

Independent $t$ tests showed no significant difference in the trait anxiety and state anxiety (4-5) and dilatation of the cervix between the two groups $(P>0.05)$. However, there was a significant difference in the state anxiety (7-8) and dilatation of the cervix $(P=0.046)$, state anxiety in the postpartum period $(P<0.001)$, and state anxiety at the exit of the postpartum period $(P=0.028)$ (Table 2$)$. 
Table 2. Characteristics of included studies in the meta-analysis

\begin{tabular}{lccc}
\multicolumn{1}{c}{ Variable } & Control group & Doula group & P-value \\
\hline Trait anxiety & $40.43 \pm 9.83$ & $38.43 \pm 11.52$ & 0.41 \\
\hline State anxiety (4-5) and dilatation of the cervix & $52.33 \pm 11.81$ & $49.63 \pm 12.86$ & 0.33 \\
\hline State anxiety (7-8) and dilatation of the cervix & $58.75 \pm 9.71$ & $52.98 \pm 15.22$ & 0.046 \\
\hline State anxiety in the postpartum period & $43.8 \pm 13.44$ & $33.4 \pm 11.44$ & $<0.001$ \\
\hline State anxiety at the exit of postpartum & $33.5 \pm 7.67$ & $28.6 \pm 11.65$ & 0.028 \\
\hline
\end{tabular}

There was no significant difference between the two groups regarding trait anxiety and state anxiety at $4-5 \mathrm{~cm}$ and $7-8 \mathrm{~cm}$ cervical dilatations (Table 3 ). Nevertheless, patients in the doula group experienced a higher proportion of mild anxiety about entering the postpartum period $(47.5 \%$ vs $15 \%)$ and exiting it (80\% vs $40 \%$ ) compared to the control group.

Table 3. Comparison of the levels of anxiety in different phases of delivery in the two groups

\begin{tabular}{|c|c|c|c|c|}
\hline \multicolumn{2}{|c|}{ Variable } & $\begin{array}{c}\text { Control group } \\
\mathbf{N}(\%)\end{array}$ & $\begin{array}{c}\text { Doula group } \\
\text { N }(\%)\end{array}$ & $\begin{array}{c}\text { P- } \\
\text { value }\end{array}$ \\
\hline \multirow{6}{*}{ Trait anxiety } & Mild anxiety & $7(17.5)$ & $11(27.5)$ & \multirow{6}{*}{0.19} \\
\hline & Middle-low anxiety & $18(45.0)$ & $18(45.0)$ & \\
\hline & Middle-high anxiety & $10(25.0)$ & $8(20.0)$ & \\
\hline & Relatively severe anxiety & $4(10.0)$ & 0 & \\
\hline & Severe anxiety & $1(2.5)$ & $3(7.5)$ & \\
\hline & Very severe anxiety & 0 & 0 & \\
\hline \multirow{6}{*}{$\begin{array}{l}\text { State anxiety in the } 4-5 \\
(\mathrm{~cm}) \text { cervical dilatation }\end{array}$} & Mild anxiety & $2(5.0)$ & $3(7.5)$ & \multirow{6}{*}{0.53} \\
\hline & Middle-low anxiety & $6(15.0)$ & $10(25.0)$ & \\
\hline & Middle-high anxiety & $8(20.0)$ & $10(25.0)$ & \\
\hline & Relatively severe anxiety & $19(47.5)$ & $12(30.0)$ & \\
\hline & Severe anxiety & $5(12.5)$ & $4(10.0)$ & \\
\hline & Very severe anxiety & 0 & $1(2.5)$ & \\
\hline \multirow{6}{*}{$\begin{array}{l}\text { State anxiety in the } 7-8 \\
(\mathrm{~cm}) \text { cervical dilatation }\end{array}$} & Mild anxiety & $1(2.5)$ & $3(7.5)$ & \multirow{6}{*}{0.22} \\
\hline & Middle-low anxiety & $3(7.5)$ & $9(22.5)$ & \\
\hline & Middle-high anxiety & $4(10.0)$ & $4(10.0)$ & \\
\hline & Relatively severe anxiety & $21(52.5)$ & $15(37.5)$ & \\
\hline & Severe anxiety & $10(25.0)$ & $6(15.0)$ & \\
\hline & Very severe anxiety & $1(2.5)$ & $3(7.5)$ & \\
\hline \multirow{6}{*}{$\begin{array}{l}\text { State anxiety in entering to } \\
\text { postpartum }\end{array}$} & Mild anxiety & $6(15.0)$ & $19(47.5)$ & \multirow{6}{*}{0.002} \\
\hline & Middle-low anxiety & $13(2.5)$ & $16(40.0)$ & \\
\hline & Middle-high anxiety & $13(32.5)$ & $3(7.5)$ & \\
\hline & Relatively severe anxiety & $3(7.5)$ & $1(2.5)$ & \\
\hline & Severe anxiety & $5(12.5)$ & $1(2.5)$ & \\
\hline & Very severe anxiety & 0 & 0 & \\
\hline \multirow{6}{*}{$\begin{array}{l}\text { State anxiety in the exit of } \\
\text { postpartum }\end{array}$} & Mild anxiety & $16(40.0)$ & $32(80.0)$ & \multirow{6}{*}{0.001} \\
\hline & Middle-low anxiety & $19(47.5)$ & $6(15.0)$ & \\
\hline & Middle-high anxiety & $5(12.5)$ & 0 & \\
\hline & Relatively severe anxiety & 0 & $1(2.5)$ & \\
\hline & Severe anxiety & 0 & 0 & \\
\hline & Very severe anxiety & 0 & $1(2.5)$ & \\
\hline
\end{tabular}


There was a significant difference in the state anxiety about entering the postpartum period $(P=0.002)$ and exiting it $(P=0.001)$.

Table 4 shows the mean pain score in different phases of delivery in the two studied groups. The mean VAS score was significantly higher in the control group at $4-5 \mathrm{~cm}$ $(86.5 \pm 11.39$ vs $78.62 \pm 14.0 ; P=0.007)$ and $7-8 \mathrm{~cm}$ cervical dilatations ( $99.0 \pm 4.41$ vs $95.0 \pm 8.47 ; P=0.01)$ stages.

Table 4. Comparison of the mean pain score in different phases of delivery in the two groups

\begin{tabular}{lccc}
\multicolumn{1}{c}{ Variable } & Control group & Doula group & P-value \\
\hline At the beginning of the study & $42.12 \pm 15.93$ & $39.75 \pm 17.01$ & 0.52 \\
Cervical dilatation: $4-5 \mathrm{~cm}$ & $86.5 \pm 11.39$ & $78.62 \pm 14.0$ & 0.007 \\
\hline Cervical dilatation: $7-8 \mathrm{~cm}$ & $99.0 \pm 4.41$ & $95.0 \pm 8.47$ & 0.01 \\
\hline Postpartum & $7.63 \pm 5.77$ & $7.0 \pm 7.66$ & 0.68 \\
\hline Exit of postpartum & $0.67 \pm 2.15$ & $1.1 \pm 2.63$ & 0.43 \\
\hline
\end{tabular}

\section{Discussion}

This randomized clinical trial was conducted to evaluate the effect of a doula's presence near pregnant women during labor on the psychological outcomes of delivery. The results revealed that the score of anxiety was reduced in the doula group compared to the control group, a difference that could be attributed to the presence of the doula. This indicates that doulas were informed about the labor process, which reduced mothers' anxiety, an effect not shown in the control group.

Also, the findings of other studies, which assessed the effect of the presence of accompaniment on anxiety, were consistent with the results of this study. Our results indicated that the anxiety score significantly differed between the two groups during and after delivery $(6,13)$. Further, the findings of another study concerning state anxiety at the time of admission were consistent with our results (10).

The results of Heaman's study showed that the mean score of anxiety during the first hours after delivery had no significant change among the groups (14); in this study, doulas receive training before delivery and were only physically existent with the mothers. However, in the present study, doulas played a vital role in labor and delivered physical and emotional support to the mothers. Thus, the doulas had an active role in decreasing pregnant women's anxiety about delivery consequences.

Another finding was that the score of pain was reduced in the doula group compared to the control group. This indicates that training doulas for the process of labor and delivery can reduce mothers' pain. The presence of doulas increases women's selfconfidence and supports them in adjusting to the pain (15). The results were similar to the findings of previous studies $(16,17)$. Ip et al. believe that intervention is effective in boosting pregnant women's self-efficacy for reducing their pain (18). The results of Melzak et al.'s study showed that intervention for pregnant women could emotionally decrease labor pain by $30 \%$ (19). This could be due to the changes in women's views and developing a positive attitude to labor. Being well educated in childbirth can make pregnant women feel comfortable and tolerate pain well (20).

The results of this study should be considered in light of its limitations. First, the results might have been affected by the pregnant women and their doulas' cultural and structural limitations. Moreover, differences in personnel's attitude and behavior to pregnant women in labor, as well as the different characteristics of parity, education, and NVD between the two groups, could have confounded the findings.

\section{Conclusion}

Generally, it is concluded that the presence of a trained doula by pregnant women's side during labor can improve the mental outcomes of delivery and decrease the women's anxiety and pain. It is suggested that the study should be replicated with a larger sample and in different health centers of Iran. It is also recommended that maternity centers should implement this low-cost and proper intervention during the delivery process.

\section{Acknowledgements}

This study was supported by the Zanjan University of Medical Sciences (ZUMS). We gratefully acknowledge the kind support of the participants for their precious collaboration, as well as the staff of Ayatollah Musavi Hospital.

\section{Availability of Data and Materials}

The datasets used and/or analyzed in the present study are available; the corresponding author could answer any reasonable requests. 


\section{Ethical Approval and Consent to Participate}

After the managers read the informed consent, the researchers explained the purpose of the study and informed the participants of their rights. Participation in this study was voluntarily and the participants could discontinue this when they were not interested in cooperating for any reason. Ethical approval for the study was obtained from the Institutional Review Board of Zanjan University of Medical Sciences according to the Declaration of Helsinki. This study was approved by the Ethical Committee of Zanjan University of Medical Sciences (reference number: zums.rec.1395.278).

\section{Funding and support}

This research resulted from an independent research without receiving any financial support.

\section{Conflict of Interests}

The authors reported no conflict of interest.

\section{References}

1. Modarressnejad V. Couples' attitudes to the husband's presence in the delivery room during childbirth. East Mediterranean Health J. 2005;11 (4), 828-34.

2. Teshome M, Abdella A, Kumbi S. Partureints' need of continous labor support in labor wards. Ethiopy J Health Develop. 2007;21(1):35-9. [DOI:10.4314/ejhd.v21i1.10029]

3. Ostovar R, Rashidi BH, Haghallahi F, Fararoei M, Rasouli M, Naeimi E. Non-medical factors on choice of delivery (CS/NVD) in hospitals of Tehran University of Medical Sciences. J Obstet Gynecol. 2013;3(01):67 [DOI:10.4236/ojog.2013.31015]

4. Iliadou M. Supporting women in labour. Health Sci J. 2012;6(3):385.

5. Arnold JA. Social support by doulas during labor and the early postpartum period. Hospital Physician. 2001:57-65

6. Salehi A, Fahami F, Beigi M. The effect of presence of trained husbands beside their wives during childbirth on women's anxiety. Iran J Nurs Midwif Res. 2016;21(6):611-5. [DOI:10.4103/1735-9066.197672]

7. Langer A, Campero L, Garcia C, Reynoso S. Effects of psychosocial support during labour and childbirth on breastfeeding, medical interventions, and mothers' wellbeing in a Mexican public hospital: a randomised clinical trial. $\mathrm{Br} \mathrm{J}$ Obstet Gynaecol. 1998;105(10):1056-63. [DOI:10.1111/j.1471-0528.1998.tb09936.x]
8. Kungwimba E, Maluwa A, Chirwa E. Experiences of women with the support they received from their birth companions during labour and delivery in Malawi. Health. 2013;5(01):45. [DOI:10.4236/health.2013.51007]

9. Sauls DJ. Effects of labor support on mothers, babies, and birth outcomes. J Obstet, Gynecol Neonat Nurs. 2002;31(6):733-41. [DOI:10.1177/0884217502239209]

10. Chunuan S, Somsap Y, Pinjaroen S, Thitimapong S, Nangham S, Ongpalanupat F. Effect of the presence of family members, during the first stage of labor, on childbirth outcomes in a provincial hospital in Songkhla Province, Thailand. Pacific Rim Int J Nur Res. 2009;13(1):16-27.

11. Schetter CD, Tanner L. Anxiety, depression and stress in pregnancy: implications for mothers, children, research, and practice. Curr Opinion Psychiatr. [DOI:10.1097/YCO.0b013e3283503680]

12. Aghamohammadi Kalkhoran M, Karimollahi M. Religiousness and preoperative anxiety: a correlational study. Ann General Psychiatr. 2007;6(1):17. [DOI:10.1186/1744-859X-6-17]

13. Toosi SZ, Mohammadinia N, Sereshti M. Effect of companionship during labor on level of anxiety of primiparous mothers and midwives points of view in Iranshahr, 2010. J Mazandaran Univ Med Sci. 2013;22(96).

14. Heaman M. A randomized controlled trial of continuous labor support for middle-class couples: Effect on cesarean delivery rates. MCN: Am J Maternal/Child Nurs. 2009;34(2):133. [DOI:10.1097/01.NMC.0000347314.98024.46]

15. Akbarzadeh M, Masoudi Z, Zare N, Vaziri F. Comparison of the effects of doula supportive care and acupressure at the BL32 point on the mother's anxiety level and delivery outcome. Iran J Nurs Midwif Res . 2015;20(2):239-46.

16. Nobakht F, Safdari DF, Parvin N, Rafiee VL. The effect of the presence of an attendant on anxiety and labor pain of primiparae referring to Hajar Hospital in Shahre Kurd. J Res Develop Nurse Midwif.2012; 9 (1): 41 -50.

17. Firouzbakht M, Nikpour M, Salmalian H, Ledari FM, Khafri S. The effect of perinatal education on Iranian mothers' stress and labor pain. Glob J Health Sci. 2013;6(1):61-8. [DOI:10.5539/gjhs.v6n1p61]

18. Ip WY, Tang CS, Goggins WB. An educational intervention to improve women's ability to cope with childbirth. J Clin Nurs. 2009;18(15):2125-35. [DOI:10.1111/j.1365-2702.2008.02720.x] 
19. Melzack R, Taenzer P, Feldman P, Kinch RA. Labour is still painful after prepared childbirth training. Canadian Med Assoc J. 1981;125(4):357.
20. Lowe NK. The nature of labor pain. Am J Obstet Gynecol. 2002;186(5):S16-S24. [DOI:10.1067/mob.2002.121427]

\section{How to Cite This Article:}

Kazemi Robati A, Molaei B, Motamed N, Hatami R, Gholami H, Ahmadi Birjandi A et al . Effects of the Presence of the Doula on Pregnant Women's Anxiety and Pain During Delivery: A Randomized Controlled Trial. J Adv Med Biomed Res. 2020; 28 (131) :316-322

\section{Download citation:}

$\underline{\text { BibTeX }}|\underline{\text { RIS }}| \underline{\text { EndNote }}|\underline{\text { Medlars }}| \underline{\text { ProCite }}|\underline{\text { Reference Manager }}| \underline{\text { RefWorks }}$

\section{Send citation to:}

(3) Mendeley 2 Zotero ORefWorks $\underline{\text { RefWorks }}$ 